\title{
Lubricating Oil Conditioning Sensors for Online Machine Health Monitoring - A Review
}

\author{
Xiaoliang Zhu, Chong Zhong, and Jiang Zhe
}

\begin{abstract}
Analysis of lubricating oil is an effective approach in judging machine's health condition and providing early warning of machine's failure progression. Many studies from both academia and industry have been conducted. This paper presents a comprehensive review of the state-of-the-art online sensors for measuring lubricant properties (e.g. wear debris, water, viscosity, aeration, soot, corrosion, and sulfur content). These online sensors include single oil property sensors based on capacitive, inductive, acoustic, and optical sensing and integrated sensors for measuring multiple oil properties. Advantages and disadvantages of each sensing method, as well as the challenges for future developments, are discussed. Research priorities are defined to address the industry needs of machine health monitoring.
\end{abstract}

Keywords: oil condition monitoring; wear debris; lubricant properties; online sensor

\section{Introduction}

Machine condition monitoring has become essential in maintaining and extending the health of high speed rotating and reciprocating machinery used in many of the nation's key industries including aerospace, manufacturing, and energy [1]. The real time condition monitoring of a machine's health status can significantly reduce the operation cost by eliminating the need for costly machine shutdowns for inspection, which would otherwise be needed to avoid the possibility of catastrophic component failure during operation. Accurate condition monitoring methodologies are being sought to facilitate the effective scheduling of maintenance and repair downtime, particularly in military and the air transport industries, to ensure the safety of long-range operations. Although vibration analysis [2] and thermography [3] have been used in detecting severe faults of rotating machinery, these methods require sophisticated data acquisition and computational procedures, which are difficult to implement. In addition, little or no vibration/temperature change can be noticed at the early stage of a fault developing. More importantly, these methods are usually ineffective in identifying machine's wear conditions and providing a prognosis of pending machine failure [4].

Lubricating oil analysis has become an effective mean to provide early warnings in the failure progression because it contains valuable information regarding the aging and damage of oilwetted moving components [5]. For lubricating oil property sensors, offline sensors require a physical sample of the lubricating oil be taken from the lubrication system and then be analyzed in the laboratory (away from the machine). In comparison, online sensors, installed on the machine, monitor a portion of the lubricating oil from the continuously circulated lubricant flow in-situ during operation. Currently, off-line measurement methods including spectrography and ferrography still remain the most commonly used strategy for diagnosing oil conditions [1]. Although offline methods can provide comprehensive and detailed information about oil conditions, the test procedures are time-consuming and often require expensive equipment and skilled analysts [2]. Furthermore, this method cannot provide real-time information about machine health that could be used for avoiding the catastrophic component failure during operation and providing a prognosis of pending machine fault. Online, portable devices that can perform real time analysis of lubricating oil with no need for complicated setup and skilled analysts are highly desired. 
been conducted in developing online oil conditioning sensors, which can provide real time and continuous monitoring of machine's health condition. Although several review papers have been published in recent years, the majority of the papers to date were focusing on sensors to test one kind of oil property or sensors (mainly offline sensors) to be used in a special machine, e.g. wind turbine. In this article, we intend to provide a comprehensive review of the state-of-the-art online sensors for measurement of the oil properties including wear debris, water, viscosity, aeration, soot, corrosion, sulfur content, etc., with a particular focus on the developments in the past five years. Advancements on online oil property sensors based on capacitive, inductive, acoustic, and optical methods for both single oil property and multiple properties measurements are reviewed. The remaining of this paper is organized as follows: In Section 2, the online sensor techniques used for measuring one oil property are reviewed. Section 3 reviews the integrated sensors for measurement of multiple oil properties. The future work to fulfill the industry need is discussed in Section 4.

\section{2. Single oil property sensors}

\subsection{Wear debris sensors}

Detection of small wear debris is critical to identify abnormal wear conditions for prognosis concentration is shown in Figure 1 [6], although wear debris size range at specific machine conditions varies with different machines. During initial/normal operation of a new engine or gearbox, the wear debris size is typically between $1 \mu \mathrm{m}$ and $10 \mu \mathrm{m}$, and the concentration remains approximately constant. When the machine is in the abnormal condition, larger debris particles between $20 \mu \mathrm{m}$ and $100 \mu \mathrm{m}$ (between $10 \mu \mathrm{m}$ and $50 \mu \mathrm{m}$ for wind turbines) are seen. The wear debris size and concentration gradually increase with machine operation time until machine fails [7]. Studies [8,9] have shown that, when debris size is larger than $100 \mu \mathrm{m}$ (comparable to the diameter of human hair), the machine is in critical conditions and an immediate machine maintenance is needed to avoid machine failure. Thus, to give an early warning of the machine conditions, debris size larger than $20 \mu \mathrm{m}$ (10 $\mu \mathrm{m}$ for wind turbines) is needed to be monitored.

Several methodologies have been adopted since wear debris present in lubricating oil changes the oil's permittivity, permeability, conductivity, and optical properties. By monitoring these parameters, the presence, size, shape, and concentration of wear debris can thus be obtained. To be noted that, some of the online sensors reviewed in the following sections are already commercialized, e.g. Gill Sensor and MetalSCAN sensor, which can be implemented in a fleet of engines or other machines to measure lubricating oil conditions during operation. Other online sensors, such as the microfluidic capacitance sensor (Section 2.1.2) and the 2-layer planar coil sensor (Section 2.1.3) are still tested in bench-top experimental setups. A summary of the wear debris sensors has been listed in Table 1.

Table 1. Summary of the wear debris sensors

\begin{tabular}{|c|c|c|c|c|c|c|c|}
\hline \multicolumn{2}{|c|}{$\begin{array}{c}\text { Monitoring methods } \\
\text { classification }\end{array}$} & $\begin{array}{c}\text { Specific } \\
\text { sensor }\end{array}$ & $\begin{array}{c}\text { Material } \\
\text { detected }\end{array}$ & $\begin{array}{c}\text { Detection } \\
\text { range }\end{array}$ & Advantage & Disadvantage & Ref. \\
\hline Inductance & $\begin{array}{c}\text { Magnetic } \\
\text { collection }\end{array}$ & Gill sensors & $\begin{array}{c}\text { Ferrous } \\
\text { debris }\end{array}$ & NA & $\begin{array}{c}\text { Clear up ferrous } \\
\text { debris, high } \\
\text { throughput }\end{array}$ & $\begin{array}{c}\text { cannot detect 1) } \\
\text { individual debris } \\
\text { particles, 2) non- } \\
\text { ferrous debris } \\
\text { particles }\end{array}$ & {$[8]$} \\
\cline { 2 - 7 } & $\begin{array}{c}3-\mathrm{D} \\
\text { solenoid }\end{array}$ & $\begin{array}{c}\text { MetalSCAN } \\
\text { sensor }\end{array}$ & $\begin{array}{c}\text { Ferrous } \\
\text { and non- }\end{array}$ & $\begin{array}{c}100- \\
3360 \mu \mathrm{m}\end{array}$ & $\begin{array}{c}\text { Differentiate } \\
\text { ferrous and }\end{array}$ & $\begin{array}{c}\text { Low sensitivity, } \\
\text { may identify }\end{array}$ & {$[16]$} \\
\hline
\end{tabular}




\begin{tabular}{|c|c|c|c|c|c|c|c|}
\hline & structure & & $\begin{array}{l}\text { ferrous } \\
\text { debris }\end{array}$ & & $\begin{array}{l}\text { non-ferrous } \\
\text { debris, high } \\
\text { throughput }\end{array}$ & $\begin{array}{l}\text { multiple debris } \\
\text { particles as one } \\
\text { large debris } \\
\text { particle due to } \\
\text { large sensing } \\
\text { zone }\end{array}$ & \\
\hline & $\begin{array}{c}\text { 2-layer } \\
\text { planar coil } \\
\text { structure }\end{array}$ & $\begin{array}{l}\text { Inductive } \\
\text { pulse sensor }\end{array}$ & $\begin{array}{l}\text { Ferrous } \\
\text { and non- } \\
\text { ferrous } \\
\text { debris }\end{array}$ & $\begin{array}{c}20-1000 \\
\mu \mathrm{m}\end{array}$ & $\begin{array}{c}\text { Can 1) } \\
\text { differentiate } \\
\text { ferrous and } \\
\text { non-ferrous } \\
\text { debris, 2) } \\
\text { individual wear } \\
\text { debris particles }\end{array}$ & Low throughput & $\begin{array}{c}{[17-} \\
19]\end{array}$ \\
\hline \multirow[t]{2}{*}{ Capacitance } & \multirow{2}{*}{$\begin{array}{c}\text { Dielectric } \\
\text { constant }\end{array}$} & $\begin{array}{c}\text { Bulk } \\
\text { capacitance } \\
\text { sensor }\end{array}$ & $\begin{array}{l}\text { Metallic } \\
\text { debris }\end{array}$ & NA & $\begin{array}{l}\text { High } \\
\text { throughput }\end{array}$ & $\begin{array}{c}\text { Low sensitivity, } \\
\text { water influence, } \\
\text { large sensing } \\
\text { zone }\end{array}$ & [13] \\
\hline & & $\begin{array}{l}\text { Microfluidic } \\
\text { capacitance } \\
\text { sensor }\end{array}$ & $\begin{array}{l}\text { Metallic } \\
\text { debris }\end{array}$ & $10-40 \mu \mathrm{m}$ & High sensitivity & $\begin{array}{l}\text { Extremely low } \\
\text { throughput, } \\
\text { water influence }\end{array}$ & [9] \\
\hline \multirow{2}{*}{ Ultrasonic } & \multirow{2}{*}{$\begin{array}{l}\text { Acoustic } \\
\text { amplitude } \\
\text { change }\end{array}$} & $\begin{array}{l}\text { Ultrasonic oil } \\
\text { debris sensor }\end{array}$ & $\begin{array}{l}\text { Solid } \\
\text { debris, } \\
\text { air } \\
\text { bubble }\end{array}$ & $\begin{array}{c}170-1000 \\
\mu \mathrm{m}\end{array}$ & $\begin{array}{l}\text { Detect solid } \\
\text { debris and air } \\
\text { bubbles }\end{array}$ & $\begin{array}{l}\text { complicated } \\
\text { structure, cannot } \\
\text { differentiate } \\
\text { metallic and non- } \\
\text { metallic debris }\end{array}$ & [23] \\
\hline & & $\begin{array}{l}\text { Integrated } \\
\text { ultrasonic- } \\
\text { inductive } \\
\text { pulse sensor }\end{array}$ & $\begin{array}{l}\text { Metallic } \\
\text { debris, } \\
\text { ceramic, } \\
\text { air } \\
\text { bubble }\end{array}$ & $\begin{array}{c}50-310 \\
\mu \mathrm{m}\end{array}$ & $\begin{array}{c}\text { Differentiate } \\
\text { ferrous, } \\
\text { nonferrous, } \\
\text { solid debris and } \\
\text { air bubbles } \\
\end{array}$ & $\begin{array}{l}\text { Low throughput, } \\
\text { complicated flow } \\
\text { recess structure }\end{array}$ & [24] \\
\hline Optical & $\begin{array}{l}\text { Wear debris } \\
\text { morphology }\end{array}$ & $\begin{array}{l}\text { Active pixel } \\
\text { sensor }\end{array}$ & $\begin{array}{l}\text { Solid } \\
\text { debris }\end{array}$ & $5-160 \mu \mathrm{m}$ & $\begin{array}{l}\text { Detect debris } \\
\text { particle shape } \\
\text { and material }\end{array}$ & $\begin{array}{l}\text { Low throughput, } \\
\text { complicated } \\
\text { system, } \\
\text { affected by oil } \\
\text { transparency }\end{array}$ & [25] \\
\hline
\end{tabular}

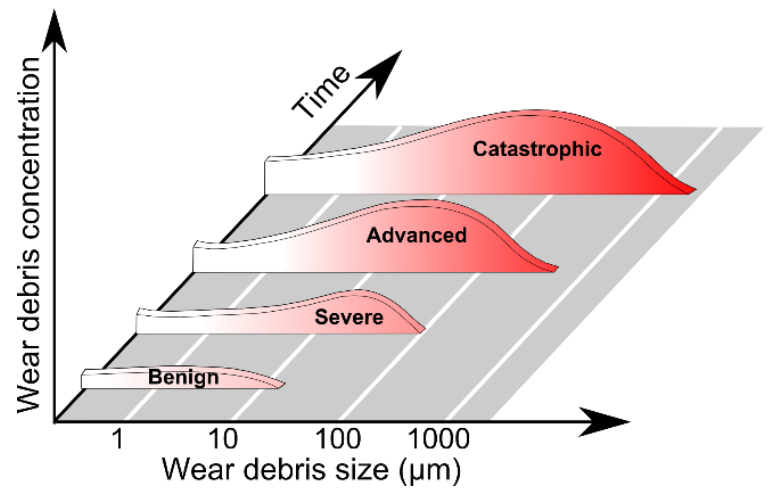

Figure 1. Relationships of wear debris size, concentration, and machine conditions

As summarized in Table 1, many wear debris sensors can be adapted to detect wear debris within a specific size range, including microfluidic capacitance sensor (Section 2.1.2), MetalSCAN sensor (Section2.1.3), 2-layer planar coil sensor (Section 2.1.3), ultrasonic-based sensor (Section 2.1.4) and optical-based sensor (Section 2.1.5). Taking the inductive sensor with a 2-layer planar coil 
for example [19], it can detect ferrous debris particles between $20 \mu \mathrm{m}$ (lower detection limit) and $1000 \mu \mathrm{m}$ (upper detection limit). A physical filter can be added in the upstream to only allow particles below a certain size to pass through and be detected. The size and count of all debris particles can be measured. Debris and counts of debris particles with a certain size range can thus be obtained.

\subsubsection{Wear debris sensors based on bulk measurement}

Wear debris includes ferrous, non-ferrous, and ceramic debris. Among wear debris, ferrous debris is the largest portion because many machine components are made of steel. Therefore, it is an important information carrier for machine's wear condition. Gill Sensors has developed a ferrous debris sensor, which has been utilized in monitoring the health of gearbox and transmission systems of land-based vehicles, to detect the ferrous debris in lubricating oil[10]. The sensor's structure is shown in Figure 2. It consists of two identical sensor units; each unit has an inductance sensing coil and a permanent magnet for collecting ferrous debris to the sensor tip. The two units, one for detecting fine ferrous debris build-up (Sensor 1 in Figure 2) and the other for detecting large ferrous debris (Sensor 2 in Figure 2), are able to determine the amount of ferrous debris build-up based on the sensing coil's inductance change. Furthermore, because of the permanent magnet, this sensor also prevents debris from continuing to travel through the oil circulation system, reducing further damage. However, this sensor relies on the bulk measurement of a large amount of ferrous debris attracted to the sensor tip over a period of time. Therefore, it cannot provide real time information about individual ferrous debris particles' size and concentration. Additionally, it is unable to detect the nonferrous debris, which is also critical to judge the condition of machines with the nonferrous coating.

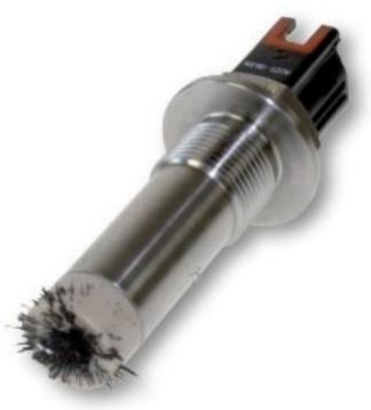

Sensor 1 , for fine metallic debris build-up for coarse metallic debris detection

Figure 2. Schematic of the ferrous debris sensors developed by Gill Sensors

\subsubsection{Wear debris sensors based on capacitive method}

In order to detect each individual wear debris particle, Murali et al. have demonstrated the a device for detecting and counting micro metallic debris in nonconductive lubricating oil inspired by Coulter counting principle, an established technique for counting and sizing debris in electrolyte solution [11]. The microfluidic device, as shown in Figure 3, consists of an inlet reservoir, an outlet reservoir, and a single fluidic channel with dimensions of $40 \mu \mathrm{m}(\mathrm{H}) \times 100 \mu \mathrm{m}(\mathrm{W}) \times 300 \mu \mathrm{m}(\mathrm{L})$. A pair of coplanar electrodes with a gap of $40 \mu \mathrm{m}$ are located in the middle of the fluidic channel. When a metallic debris particle is passing through the microchannel, a capacitance change is detected owing to the permittivity differences between the wear debris and the lubricating oil. Compared with Gill Sensors and other bulk capacitance sensing methods [12-14], which has a simple structure but a 
very large sensing zone, this microfluidic capacitive sensor can measure wear debris $(10 \mu \mathrm{m}$ to 25 $\mu \mathrm{m})$ individually.
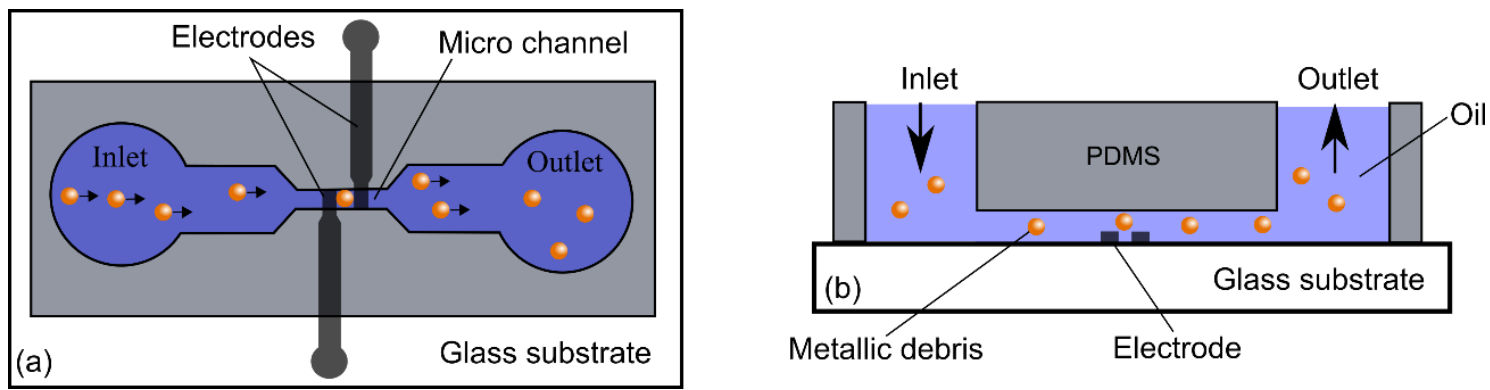

Figure 3. Schematic of a capacitive oil debris sensor with a microfluidic channel [11]. (a) top view.

(b) sectioned side view.

Although this device can detect wear debris as small as $10 \mu \mathrm{m}$, it has the following disadvantages. First, the sensor is unable to differentiate ferrous and nonferrous wear debris since these debris particles have a similar permittivity. Second, the measured capacitances also reflect the change in acid number content and viscosity, creating difficulties in detecting debris. Third, while air bubbles $\left(\varepsilon_{a i r}=1.0\right.$, compare with $\left.\varepsilon_{o i l} \sim 2.0\right)$ have no noticeable influence on the output of the sensor, water droplet could generate a large capacitive pulse because water's relative permittivity $\left(\varepsilon_{\text {water }}\right.$ 80.0 , under room temperature) is much larger than that of lubricating oil. The ultra-low throughput is another challenge for this device owing to the use of a micro-sized microchannel. Therefore, its capability for real time wear debris monitoring is limited.

\subsubsection{Wear debris sensors based on inductive method}

In an attempt to differentiate ferrous and non-ferrous debris as well as to eliminate the influences caused by air bubbles and water droplets, inductive sensors based on 3-D solenoid coils were developed. Its general working principle is illustrated in Figure 4. The inductance change of the sensor is determined by two factors, namely magnetic permeability and eddy current $[15,16]$. If a non-ferrous conductive metallic debris particle is present in the magnetic field (Figure 4 (a)), an eddy current is induced inside the debris to oppose the existing magnetic field; this decreases the total magnetic flux, leading to a decrease of the coil's equivalent inductance. On the other hand, if a ferrous conductive metallic debris particle is introduced into the coil (Figure 4 (b)), the two aforementioned factors work in a competing way. While the high relative permeability increases the magnetic flux, the eddy current causes a decrease of the magnetic flux. At low frequencies, however, the induced eddy current is small, making the total magnetic flux to be dominated by the debris' magnetic permeability. Thus, the coils' inductance is increased by the passage of a ferrous debris particle. In comparison, the coils' inductance is decreased by the passage of a nonferrous debris particle because of the dominance of the eddy current effect at higher frequencies. In this way, the ferrous and non-ferrous debris particles can be differentiated at an appropriate frequency, which is important for condition monitoring of rotating and reciprocating machinery. Air bubble and water droplet do not cause an observable inductance change because 1) the permeabilities of air (1.0000037) and water (0.99999992) are similar to oil ( 1.0) [15], and 2) the electrical conductivities of air and water are approximately $10^{-21}$ and $10^{-9}$ times that of metallic debris; thus, their eddy current effects are negligible. 

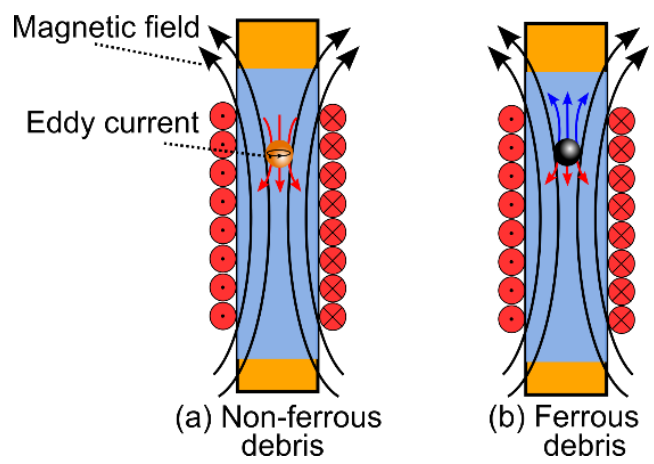

Figure 4. Illustration of the sensing mechanism for inductive sensors. (a) Magnetic flux (black lines) induced in the solenoid coil is attenuated owing to the eddy current generated magnetic flux (red lines) in the non-ferrous debris. (b) For ferrous debris, magnetic flux is enhanced owing to high relative permeability (blue lines) but also attenuated owing to eddy current

Several online wear debris sensors have been developed based on the 3-D solenoid structure, which can detect ferrous debris as small as $100 \mu \mathrm{m}[16,17]$. For example, the MetalSCAN oil debris sensor of GasTOPS has been utilized in the wind turbine gearbox and aero-derivative gas turbine engines. However, the 3-D solenoid structure does not have the ability to detect wear debris below $100 \mu \mathrm{m}$ (e.g., $20 \mu \mathrm{m}$ to $50 \mu \mathrm{m}$ ), which is critical to provide early warnings for abnormal machine conditions [7]. On the other hand, because of the large sensing zone, 3-D solenoid structure has a difficulty in detecting individual wear debris particles. If multiple small debris particles are present in the sensing area at the same time, they are most likely identified as one large debris particle, which may induce possible false positive of machine failure. In order to solve this problem as well as to detect smaller debris, Du et al. [18-20] developed a 2-layer planar coil based inductive sensor, as illustrated in Figure 5 (a). The 2-layer planar coil was assembled around a glass tube $(1 \mathrm{~mm}$ inner diameter and $1.2 \mathrm{~mm}$ outer diameter) between two glass slides. The use of the 2-layer planar coil dramatically reduced the sensing zone; the sensitivity was also improved comparing to the 3-D solenoid structure with the same turns of the coil. Figure 5 (b) illustrates the sensing zone of the 3-D solenoid and the 2-layer planar coil. Because the 2-layer coil concentrates the magnetic flux to a smaller volume (increasing the magnetic flux density), this structure can detect iron debris as small as $50 \mu \mathrm{m}$ [7] However, one limitation is its low throughput: the sensor can only process $3 \mathrm{~mL} / \mathrm{min}$ with a single channel. To increase the throughput, oil debris sensors with multiple sensing channels have been developed by Zhe's research group [21,22]. Frequency/time division multiplexing has been demonstrated effective in measuring signals from multiple sensing channels without much increasing the complexity of measurement circuit. The highest throughput achieved was reported to be $460 \mathrm{~mL} / \mathrm{min}$, which can be potentially increased to $4.1 \mathrm{~L} / \mathrm{min}$ by using additional sensing channels. Such a high throughout is suitable for online machine health monitoring [22]. Another limitation of inductive-type oil debris sensors is that they cannot detect non-conductive wear debris (e.g. ceramic debris from ceramic coatings), which is also true for the capacitive wear debris sensors. 


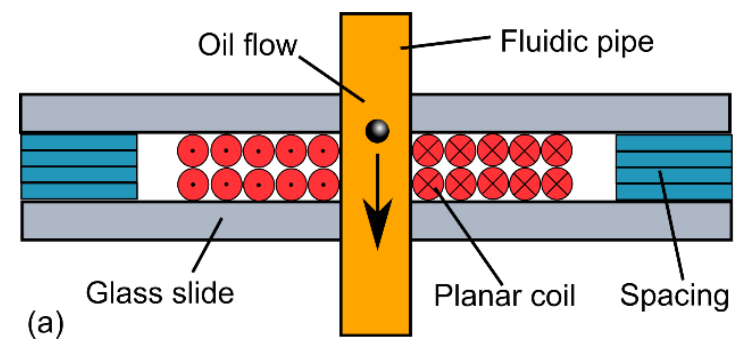

\subsubsection{Wear debris sensors based on acoustic method} does not pass the focal zone of the ultrasonic pulse sensor.

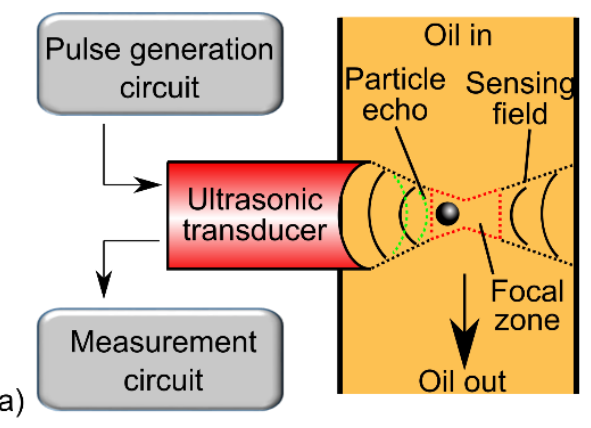

Figure 5. (a) schematic of the 2-layer planar coil inductive sensor and (b) comparisons of sensing zone between 3-D coil and planar coil structure [18]

Acoustic detection method uses single or dual ultrasonic transducers to radiate a large amplitude radio frequency pulse and receive the echoes generated by the debris particle in the flow stream. Debris size can be obtained based on the echo signal's amplitude; the larger the amplitude, the larger the debris size. The main advantage of the acoustic detection method is that it is capable of detecting and discriminating solid debris from air bubble [23-25]. As shown in Figure 6 (a), when an incident acoustic pulse encounters a debris particle, a small echo (a reflection of the incident acoustic pulse) is generated by the debris particle. Because of the differences in reflection coefficient (negative for air bubble and positive for solid debris), echoes reflected by air bubbles invert the incident pulse while echoes from solid debris particles remain non-inverted, as shown in Figure 6 (b). Therefore, air bubbles and solid wear debris can be separated by observing whether the maximum positive peak value occurs before the maximum negative peak value. However, the drawback of this method is that it is difficult to differentiate metallic debris from dielectric debris because all solid debris particles have similar acoustic reflection coefficient ( 0.93) [25]. More importantly, because the acoustic sensing field is non-uniform, the size of a debris particle may be underestimated if it

(b)

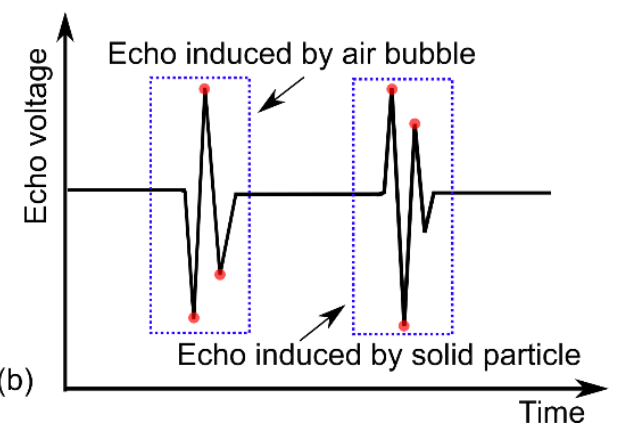

Figure 6. (a) illustration of a single transducer ultrasonic sensor and (b) sensor response for air bubble and solid debris [25]

To overcome the above two drawbacks, Du and Zhe demonstrated a proof-of-concept wear debris sensor with the integration of an inductive pulse sensor and an ultrasonic pulse sensor in series [25]. The ultrasonic pulse sensor was used to count all solid debris particles while the inductive pulse sensor was used to detect only the ferrous and non-ferrous debris. Figure 7 shows the schematic of the integrated sensor. The combination of the inductive and ultrasonic pulses allows the differentiation of dielectric, ferrous and nonferrous debris. The inductive sensor is made of 2-layer planar coils wound around a $1 \mathrm{~mm}$ diameter glass tube; the ultrasonic pulse sensor uses a spherically 
focused ultrasonic transducer for generating a focused beam and receiving the reflected acoustic echoes. To minimize the debris sizing error due to the non-uniform acoustic field in the fluidic pipe, a unique flow recess structure was used to force all debris particles to pass the focal zone, as shown in Figure 7.

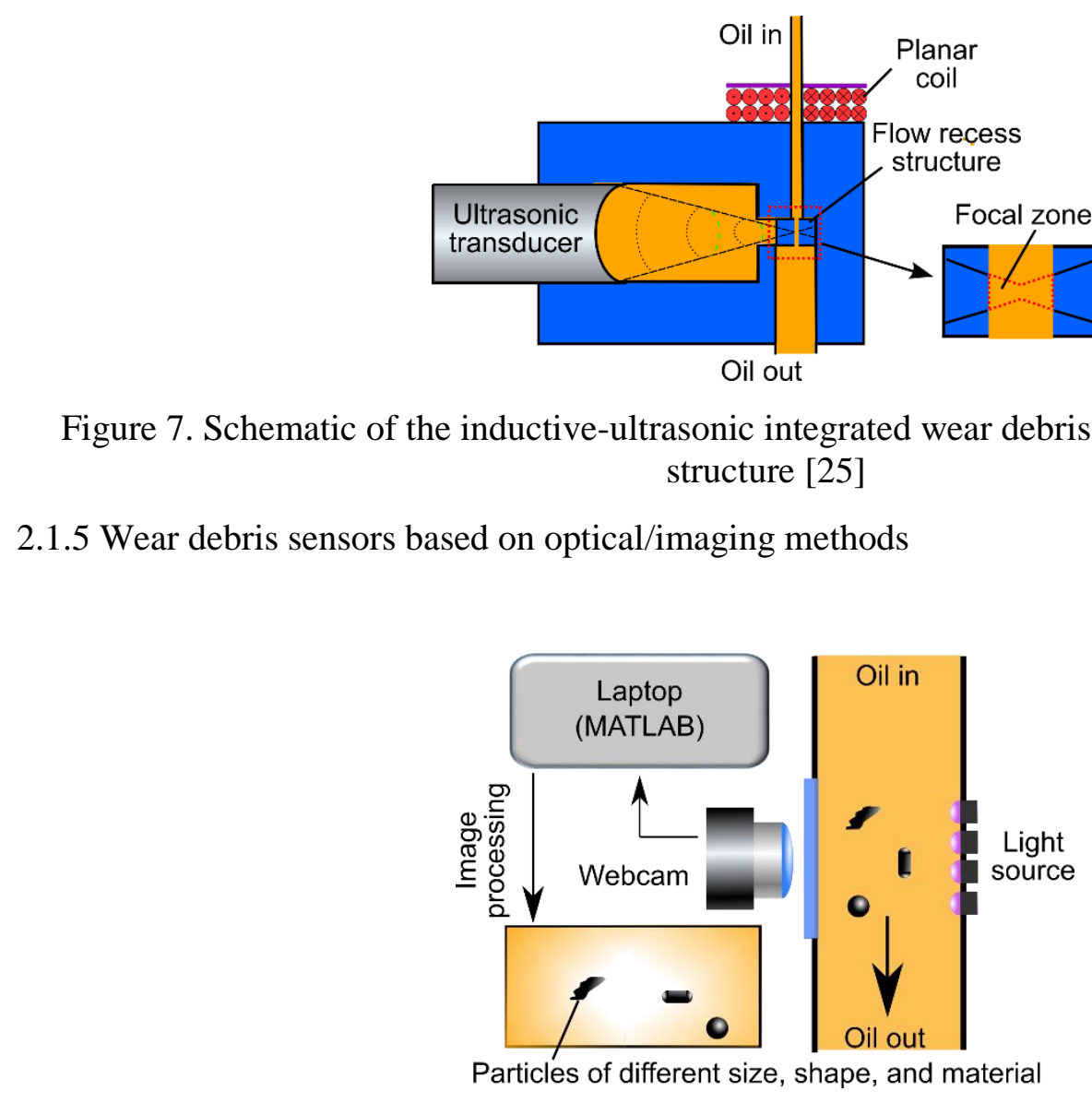

Figure 7. Schematic of the inductive-ultrasonic integrated wear debris sensor with a flow recess
structure [25]

Figure 7. Schematic of the inductive-ultrasonic integrated wear debris sensor with a flow recess
structure [25]

2.1.5 Wear debris sensors based on optical/imaging methods

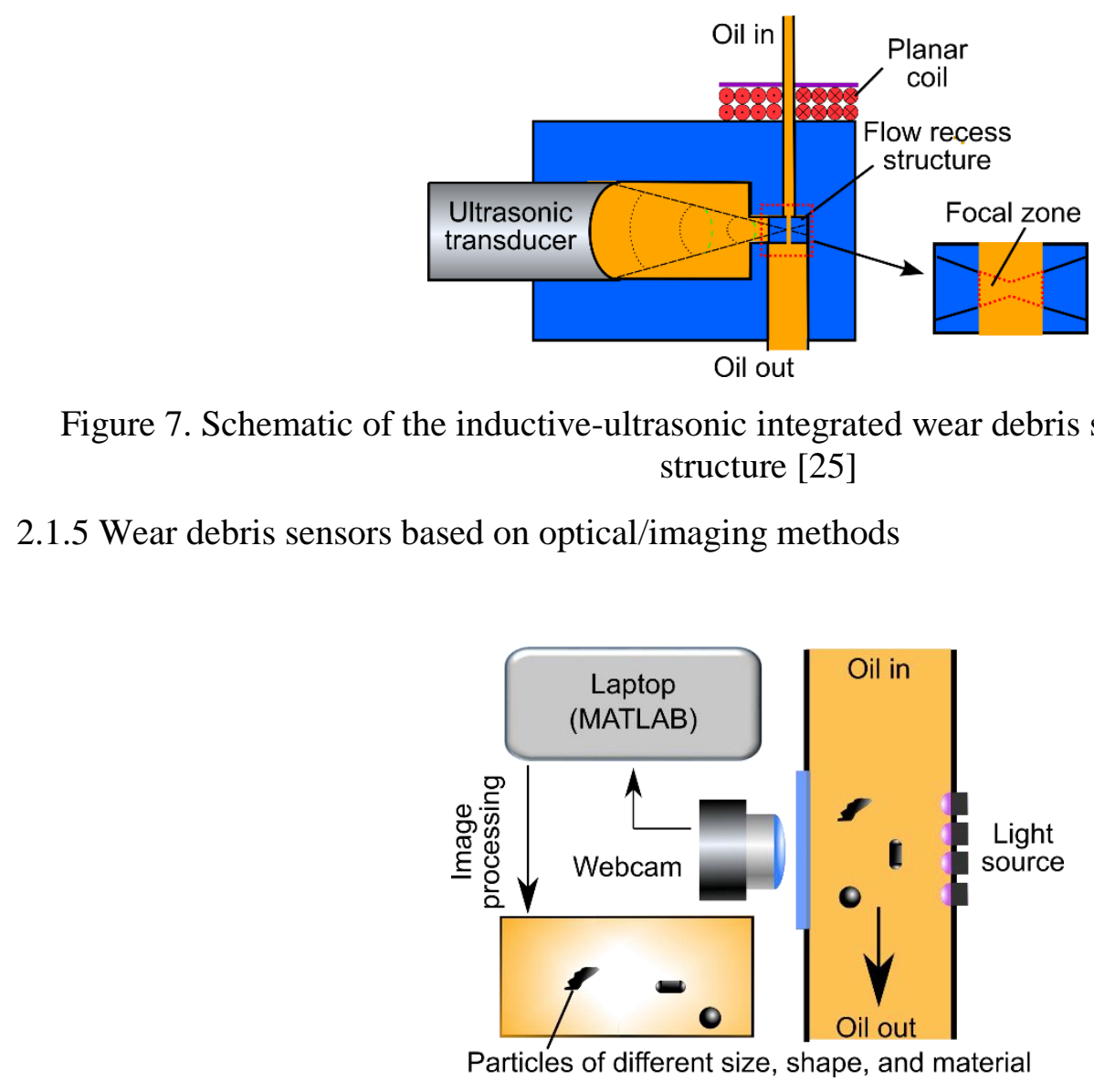

(1)

\section{Figure 8. Diagram of the webcam-based wear debris sensor developed by Hamilton et al. [26]}

Debris present in the lubricating oil affects the oil's light transmission property. Thus, wear debris can be measured in terms of measuring light transmission. Based on the light transmission measurement, different techniques, including microscopy and laser scattering, have been developed [27-29]. Hamilton et al. [26] developed a wear debris image system to detect the wear debris size and shape. As Figure 8 shows, it consists of a light source, a flow channel, and a high speed web camera. The light source is used to illuminate the flow channel; the webcam constantly takes images with a high speed as oil with wear debris passes the light source. These images are then processed with MATLAB to get individual debris particles' size and shape information, which are critical to identify mechanical faults and worn components. Wu et al. also developed a similar system to extract the wear debris particles' material information [28]. However, this method has many drawbacks when used for online applications. Firstly, lubricating oil may quickly become nontransparent after the operation, causing difficulties in taking clear pictures and errors in counting and sizing wear debris. Secondly, the system demands high performance hardware and efficient image processing algorithms to distinguish wear debris when debris particles move at a high speed or overlap in the detection window. 
2.2 Viscosity sensors

Viscosity, which indicates the lubricating oil's capability to provide a sufficient thickness of oil film between two moving surfaces, is another critical parameter that indicates the status of the lubricant and the machine. Changes in lubricant properties due to oil oxidation, fuel contamination, and additive depletion cause an abnormal viscosity change. The inappropriate viscosity of lubricating oil leads to excessive wear, unnecessary fatigue or even catastrophic engine failure [30,31]. Dynamic viscosity $(\eta)$ and kinematic viscosity $(v)$ are usually used to define the lubricant viscosity, where dynamic viscosity is the ratio of the shear stress between the lubricant layers to the transversal gradient of velocity, and kinematic viscosity is the ratio of dynamic viscosity to lubricant density [32]. It is worth noting that viscosity is significantly affected by temperature; viscosity decreases 11 with an increase in temperature.

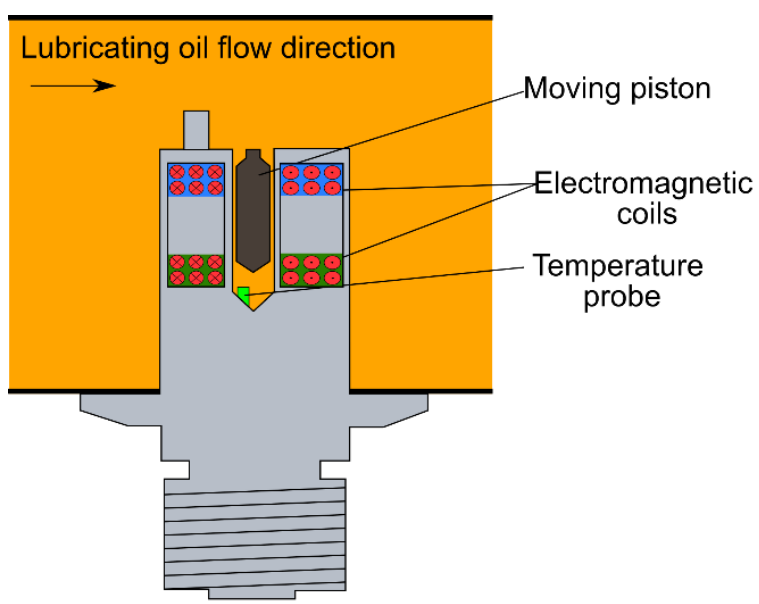

(a)

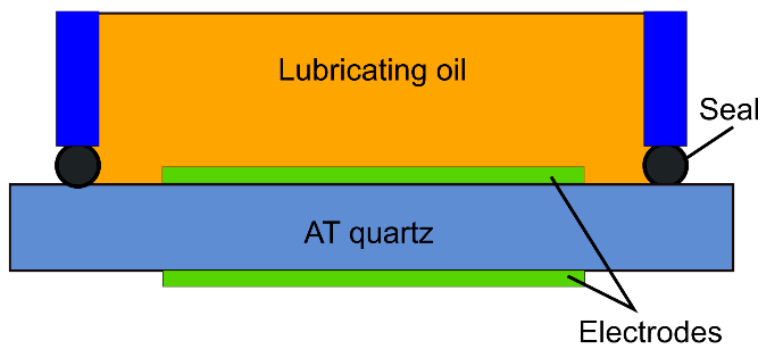

(b)

Figure 9. Schematic of the viscosity sensors based on (a) sensing body movement, and (b) acoustic wave [32]

The widely used methods for online viscosity measurement can be divided into three categories based on: 1) sensing body displacement [33], 2) acoustic [34-38], and 3) vibrational $[39,40]$ methods. Figure 9 (a) shows a typical online viscosity sensor based on sensing body displacement. A ferromagnetic piston is placed inside a chamber where two electromagnetic coils are located at top and bottom. The two coils are switched on and off alternatively; this produces a force causing the piston moving between the two coils. Lubricant viscosity can be obtained from the piston's moving time between the two coils. The reliability of this sensor, however, is decreased by the great complexity and the presence of the moving piston. An alternative approach for online viscosity measurement is based on acoustic wave. For these viscometers, piezoelectric materials are used to generate acoustic waves by an alternating electrical field [33]. Figure 9 (b) illustrates the simplest yet widespread viscometers based on quartz crystal microbalance (QCM), consisting of an AT-cut quartz disk ( 500 $\mu \mathrm{m}$ thickness) with two circular electrodes deposited on both of the substrate surfaces. The application of an external alternating voltage $(1 \sim 10 \mathrm{MHz})$ on the two electrodes produces an alternating shear deformation of the substrate and induces an acoustic wave that propagates perpendicularly to the substrate. The lubricant viscosity exerts an influence on the QCM's resonant frequency by the following equation [35]: 


$$
\Delta f^{2}=-\frac{\rho \eta f_{0}^{3}}{\pi \mu_{s} \rho_{s}}
$$

where $\rho$ is the lubricant density, $\eta$ is the viscosity, $f_{0}$ is the QCM's resonant frequency without loading, $\mu_{s}$ is the crystal shear modulus, $\rho_{s}$ is the crystal density, and $\Delta f$ is the frequency shift due to the viscous loading. By measuring the resonant frequency shift, the viscosity can be measured. Although QCM viscometer is remarkable for its simple structure and thermal stability [32], the top electrode being in contact with the lubricant might get corroded by the acid components in lubricant, decreasing its accuracy and service time. Micro-acoustic solid-state viscometers have a good potential to be embedded in lubricating oil condition monitoring system because the lubricating oil's viscosity and density are highly correlated to the oscillatory parameters [36, 37, 38]. Heinisch et al. [40] developed an online viscosity sensor using commercially available tuning forks (75.1 mm (length) by $13.7 \mathrm{~mm}$ (width)). As shown in Figure 10, the tuning forks, made of steel and corrosionresistant gold coating, are sealed in a glass tube. An electromagnet, placed outside the glass tube and close to the end of one prong, is used for generating magnetic force and hence the mechanical excitation. At the end of the other prong, an electrodynamic pick-up coil with a permanent magnet in the center of the coil is placed. When a sinusoidal voltage with a DC offset is applied, the electromagnet attracts the tuning forks periodically. The right prong, as shown in Figure 10, vibrates along the pick-up coil's axis direction, generating an induced voltage in the pick-up coil. Viscosity can thus be measured because it affects the vibration of the tuning fork. The tuning fork viscosity sensor is low cost, robust, easy to install and use, and is unaffected by the presence of air bubbles. However, its bulky size and multi-component structure limit its usage for online measurements.

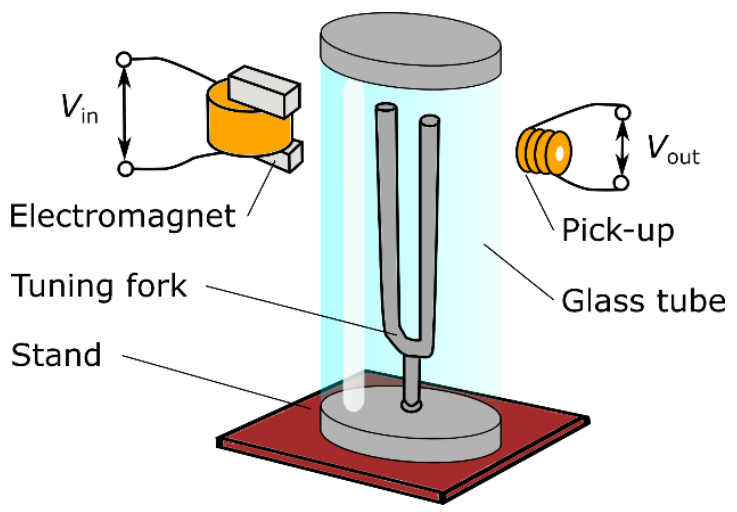

Figure 10. schematic of the tuning fork viscosity sensor [40]

It is worth mentioning here both acoustic and vibrational viscometers detect the change in resonant frequency and/or amplitude change, and the liquid's viscosity can be calculated from the change of resonance frequency or amplitude. However, a large difference between the two types of sensors is their resonance frequency ranges: ultrasonic viscometers have resonance frequencies ranging from $1 \mathrm{MHz}$ to several hundreds of $\mathrm{MHz}$, while vibrational viscometers generally have lower resonance frequency $(1 \mathrm{kHz}$ to $100 \mathrm{kHz}$ ). Although prone to pick up noise caused by capacitive coupling [39], vibrational viscometers (e.g. tuning fork) allow individual measurements of mass density and viscosity [40]. Within comparison, the QCM resonant viscometers typically provide a viscosity-density product (as shown in Equation 1) [35]. 


\subsection{Water/moisture content sensor}

According to a locomotive engine problem audit, water/moisture contamination, typically

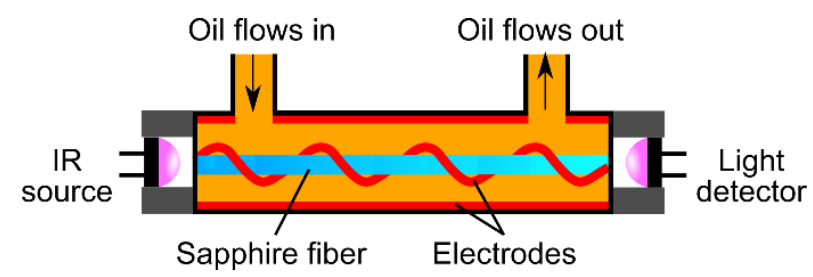

Figure 11. Setup of the evanescent-field fiber sensor developed by Holzki et al. [48]

\subsection{Soot sensors}

Soot particles are microscopic carbonaceous particles that are the product of incomplete combustion of hydrocarbons. Most soot particles are absorbed by lubricant and relatively few are exhausted $[49,50]$. Although individual or primary soot particles from diesel combustion are around $40 \mathrm{~nm}$ in diameter, they can agglomerate up to a maximum of approximately $500 \mathrm{~nm}$ because of its colloidal properties, causing an increase in the viscosity, and eventually leading to a significant 
increase of engine wear [51-53]. A high concentration of soot content can also increase the local acidity level [54], or even worse, cause oil starvation on tribological surfaces [55].

Currently, however, very little is reported on using online sensors to directly measure the soot content. This is because soot content measurement is mainly in terms of monitoring the change in lubricant's conductivity and/or permittivity. However, because of the overlapping problem, i.e. the changes in conductivity and permittivity can be caused by changes of many oil properties, rather than a specific one, these electrochemical sensors cannot pinpoint the soot content change individually. To solve this problem, Ulrich et al. [56] explored a combination of electrochemical impedance spectroscopy (EIS) and multivariate data analysis to simultaneously predict the soot concentration and diesel in engine oil. EIS, also known as dielectric spectroscopy, measures the impedance as a function of frequency and the dielectric property of the medium [53]. Figure 12 shows the schematic of the measurement setup. Two stainless steel electrodes, separated by two glass slides, are connected to an impedance analyzer. Oil samples with different soot content $(1 \% \sim 4.3 \%)$ and diesel content $(1 \%$ $\sim 5.1 \%$ ) were then added to the space between the two electrodes. The resistance and reactance were measured at 24 different frequencies ranging from $24 \mathrm{~Hz}$ to $600 \mathrm{kHz}$. After this, partial least squares (PLS), a generalization of multiple linear regression method, was used to construct two models from the reactance and resistance data; one model for predicting soot concentration and the other for diesel concentration. Although the authors claimed that this method can differentiate soot and diesel contents, other contaminants in an oil sample, such as water, wear debris, and sulfur etc., may also introduce impedance change, and possibly cause large prediction errors.

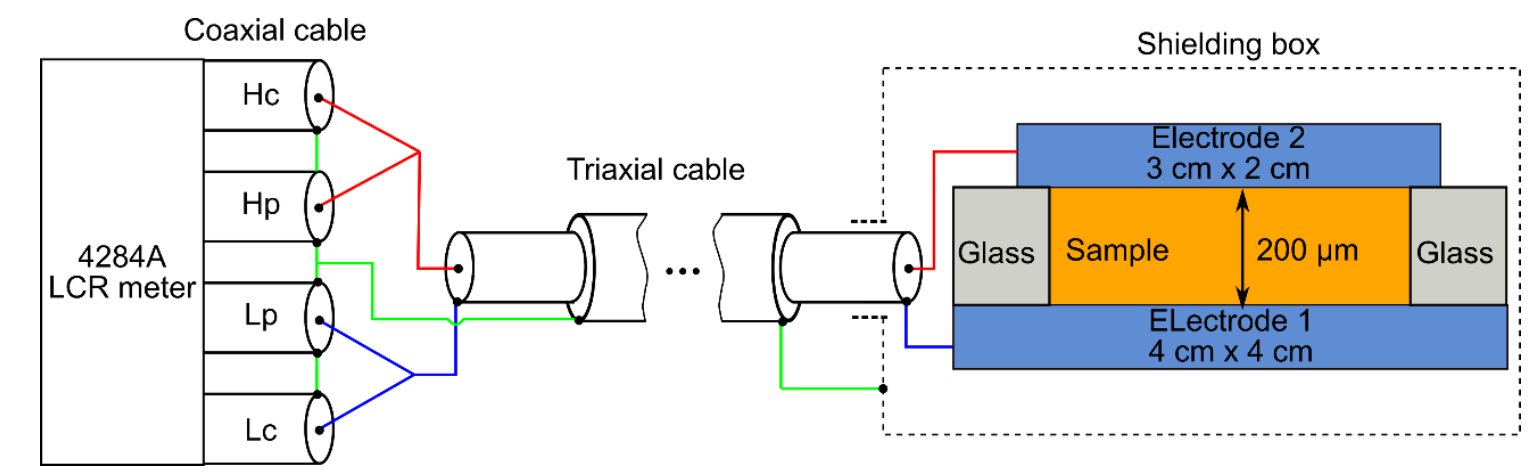

Figure 12. Schematic of the EIS measurement setup for determining soot and diesel contents by Ulrich et al. [56]

\subsection{Oil acidity/basicity sensor}

Lubricating oil degrades gradually as a result of its exposure to high temperature, water, air, and acid contaminants (combustion byproducts such as sulfuric acid, nitric acid) [57], causing oxidation of the oil. When engine oil starts to oxidize, alkyl radicals are formed and then further transformed into peroxy radicals in the presence of oxygen. The peroxy radicals further react with oil and form hydroperoxides and alkyl radicals. As this chain reaction continues, a high concentration of hydroperoxides is formed, which accelerates the oxidation [58]. Generally, the lubricating oil's total acid number (TAN) increases and the total base number (TBN) decreases during use. The increase in TAN is related to the continued oxidation and acid contamination of the oil while the decrease of TBN is caused by the degradation of antioxidants (lubricant additives) [57]. The acid contamination and loss of antioxidants typically cause a loss of performance and eventual failure of the lubricating oil. Therefore, development of an online sensor capable of monitoring changes of TAN becomes 
important in ensuring more efficient and safer machine operation. It is worth mentioning here that traditional glass $\mathrm{pH}$ sensors cannot be used here because of their slow response and low stability in the hydrocarbon environment [57].

Solid state ion selective electrode (ISE), invented over 50 years ago, has shown promise in
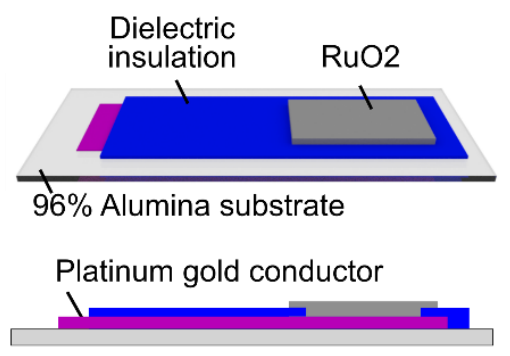

Working electrode
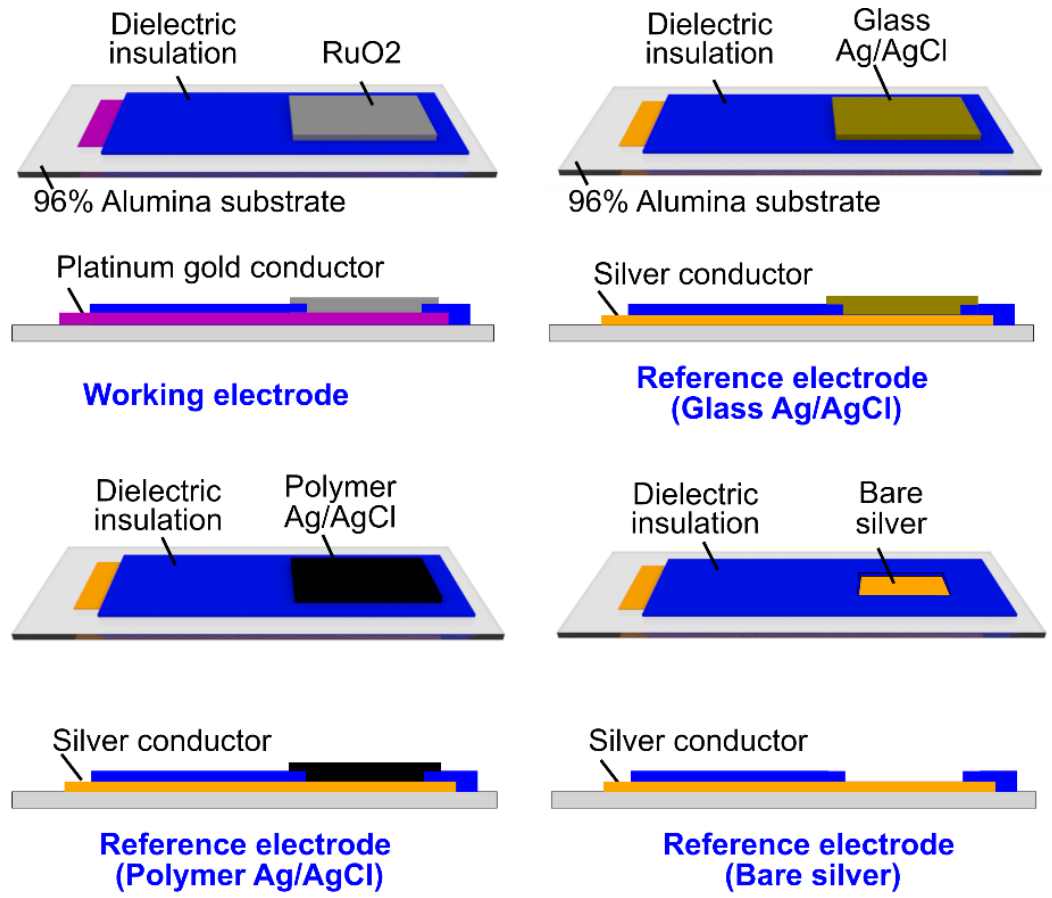

(a)

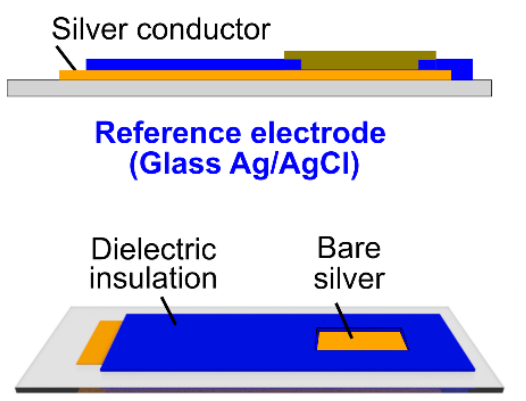




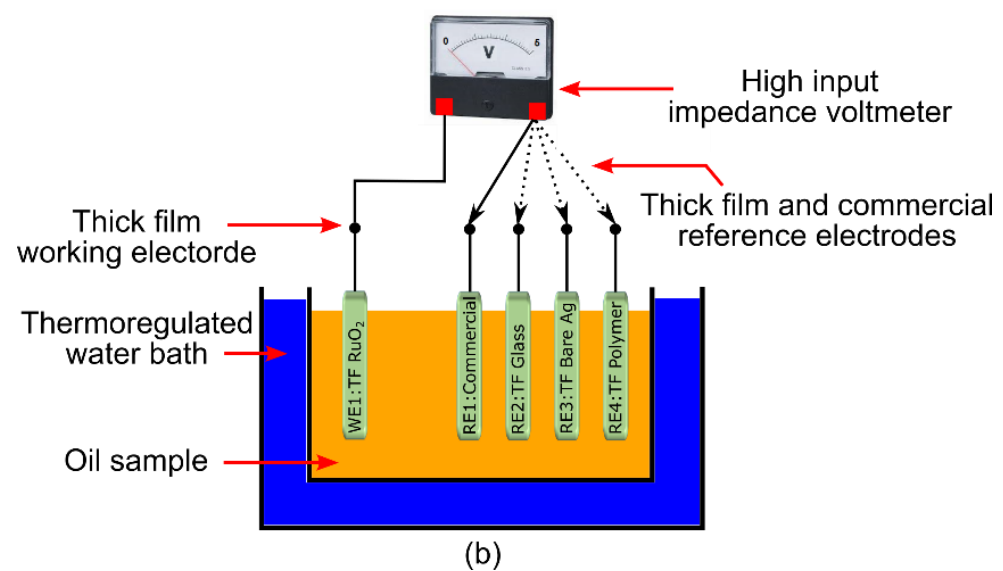

Figure 13. (a) Top view and cross section view of the working electrode, reference electrodes with glass $\mathrm{Ag} / \mathrm{AgCl}$, Polymer $\mathrm{Ag} / \mathrm{AgCl}$, and bare silver, and (b) schematic drawing of the test setup [59] 4

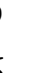

(1)

\subsection{Aeration sensor}

Figure 14. Schematic of the CNT oil sensor for total acid number measurement [61]

Air can get into the oil circulation system (oil aeration) as lubricating oil passes through the bearings and gears [62]. The study shows that the lubricating oil can contain as much as $15 \%$ (v/v) dispersed air on its way back to the oil sump, where most of the air bubbles rise and escape from the oil [63]. The degree of aeration is even severe for high speed engines because of the high air ingestion and low residual time in the oil sump. Entrained air, however, if not reduced to $1 \%$ or less before it gets into the oil pump, leads to a loss of lubrication in moving components, and increase wear and oil oxidation. Therefore, there is an increasing demand to monitor the oil aeration rate before oil gets into the oil pump.

Kimura et al. [64] developed a method to measure both aeration rate and bubble diameters in lubricating oil using image analysis. Figure 15 (a) shows the mechanism of the developed system. A small transparent viewing window was opened on the engine wall. Pictures of the lubricating oil inside the viewing window were taken using a metal halide light source and a CCD camera. The software was implemented to recognize bubbles and calculate aeration rate automatically. While a high accuracy has been reported in a laboratory environment, this method relies on picture quality. Large errors are likely to be included by transparency, light intensity, and camera/engine vibration. DSI-Deltabeam introduced an X-ray absorption method to perform online aeration measurement [65]. The operation principle, as shown in Figure 15 (b), is based on the fact that air has negligible X-ray absorption in comparison to engine oils. For the fixed volume between the two viewing windows, the aeration can thus be calculated by 


$$
x=\frac{\log \frac{I}{I_{0}}}{\log \frac{I_{1}}{I_{0}}}
$$

where $x$ is the aeration, $\mathrm{I}_{0}$ and $\mathrm{I}_{1}$ are $\mathrm{X}$-ray intensities measured at full oil $(x=0)$ and full air $(x=1)$ for the fixed volume. This method has been demonstrated to have a high accuracy. Additionally, less than $0.5 \mathrm{~L}$ of oil is needed for the analysis, which would unlikely cause an oil shortage of machinery on the original machine oil circulation system. However, the accuracy is also affected by other contaminants present in the oil, such as soot particles and water, which have different X-ray absorption behaviors in comparison to oil. In addition, the system is bulky $(60 \mathrm{~cm} \times 50 \mathrm{~cm} \times 40 \mathrm{~cm})$ and heavy $(40 \mathrm{~kg})$, and has high power consumption $(1 \mathrm{~kW})$, making it impractical for automobiles and wind turbines.

(a)
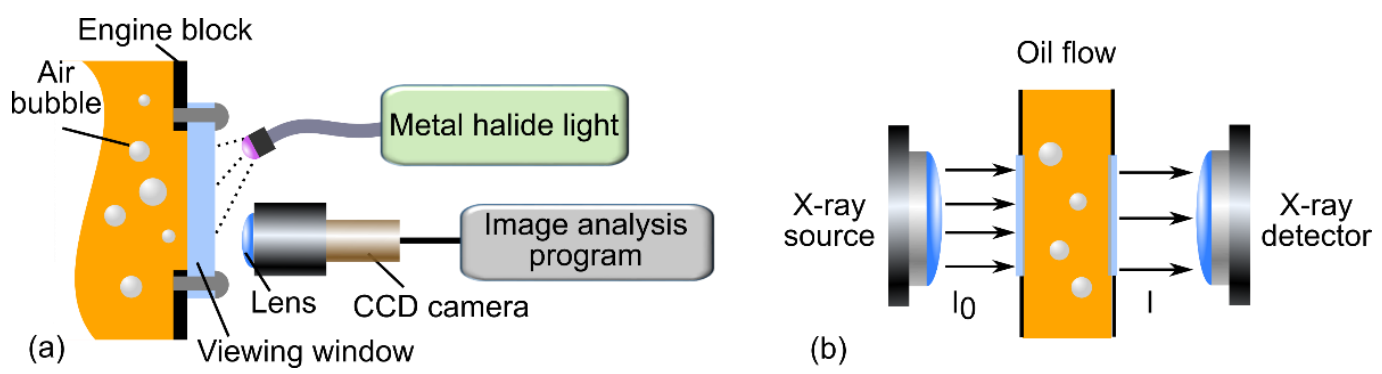

Figure 15. Illustrations of the aeration sensors based on (a) image analysis [64] and (b) X-ray absorption [65]

\subsection{Grease lubricant condition monitoring}

Grease lubricants, typically consisting of $85 \%$ base oil, $10 \%$ thickener, and 5\% additives [66], have been widely used in lubricated rolling bearings. Grease also suffers from severe physical and chemical degradations caused by thermal and mechanical effects, as well as the presence of wear debris and excess water content [67]. However, grease condition cannot be monitored by most of the online sensing methods developed for lubricating oil because 1) grease does not flow uniformly or circulate in bearings due to its non-flow, semi-solid property, and 2) it is difficult to install sensors and have them function in the bearing chambers with harsh operation conditions (e.g., high pressure, high temperature, large shocks etc. $[68,69]$ ) in order to monitor the grease condition. To date, offline methods including wet chemical analysis and spectroscopic analysis still remain dominant in analyzing the grease properties. For example, Cann et al. [70] used Fourier transform infrared spectroscopic analysis to measure grease degradation in deep groove ball bearings.

Recently Schaeffler Group developed a sensor to monitor the online condition of grease in rolling bearings. Four properties of the grease (water content, opacity, wear and temperature) [71] were measured. The sensor is based on the near-infrared reflection principle. The sensor was installed on the inner surface of rolling bearings. As shown in Figure 16, near-infrared light is emitted from two light-emitting diodes (LED), reflected by the grease, and is measured by the measurement detector. At the same time, a reference detector measures the reflected light that does not have any contact with the grease at the same temperature. From the absorption and transmission changes of the near infrared spectrum, the four parameters can be evaluated by comparing the signal from the measurement detector with the signal from the reference detector. However, the sensor head must be embedded in the grease. It is a challenge to install the sensor in the appropriate position in 
the bearing as the measurement results are sensitive to the position of the sensor. Furthermore, this method is likely to have difficulties in differentiating contaminants that have similar absorption characteristics [72]. For example, the infrared absorption is recorded in the 3600 to $3400 \mathrm{~cm}^{-1}$ range and may not be used to differentiate water, glycol or antioxidant additives, because their absorption characteristics are usually similar and overlapping.

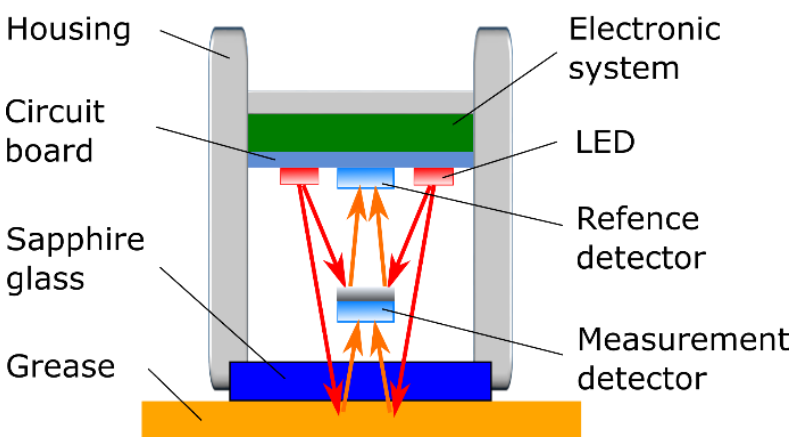

Figure 16. Schematic design of the online grease sensor [71]

Vibration analysis in the frequency domain [73] can be used to online monitor wear and health conditions of the grease lubricated bearings. Vibration analysis has been used for machine health monitoring for decades [74-77]. Bearings generate vibration during operation. When abnormal wear or damage occurs, the vibration signal differs from standard vibration signal under normal condition. By analyzing the vibration signal in the frequency domain, possible defect frequencies could be present and thus the bearings condition could be obtained. Although vibration analysis has been utilized for years, the method 1) needs installation of multiple vibration sensors (accelerometers) in several positions around the bearing [78], 2) relies on complicated signal processing and data analysis methods (e.g. wavelet transform [79], multivariate statistics [80], etc.), and 3) is insensitive to early signs of abnormal wear or grease starvation, making it unsuitable for early fault detection [81].

\section{Integrated oil properties sensors}

Lubricating oil degradation is a very complex and complicated process and it is inadequate to assess its condition just monitoring a single property [82], such as viscosity, wear debris concentration, water, and soot contents, etc. In an attempt to provide a comprehensive evaluation of the lubricating oil, a few multi-property sensors were developed. Preethichandra and Shida [83] developed a multifunctional sensor, as shown in Figure 17, using a phototransistor to measure oil cleanliness, a rotating disk to measure viscosity, and the capacitance between the fixed and rotating aluminum plate to measure oil permittivity. Note it is difficult to detect wear debris and individual oil properties using the capacitance measurement methods because the capacitance is influenced by a combination of soot, wear debris, acid/base depletion etc. Additionally, using a rotation part driven by a motor makes the system bulky and impractical for online measurement. Duchowski and Mannebach developed an oil condition monitoring device consisting of four separate components: a quartz crystal microbalance (QCM) component for viscosity measurement, two capacitive sensors for measuring total acid number (TAN) and moisture, and a thermo-resistor for temperature 
measurement [84]. Due to the complex nature of oil chemical properties, the measured capacitance change or dielectric constant change are affected not only by moisture and total acid number, but also by other oil properties (wear debris, soot component, etc.). Hence the measurement may be inaccurate for actual lubricating oil where many contaminants are present. Additionally, the output of each sensor component has to be measured separately. If a large number of sensor components are used, implementation of detection electronics would be complex and impractical for online machine health monitoring.

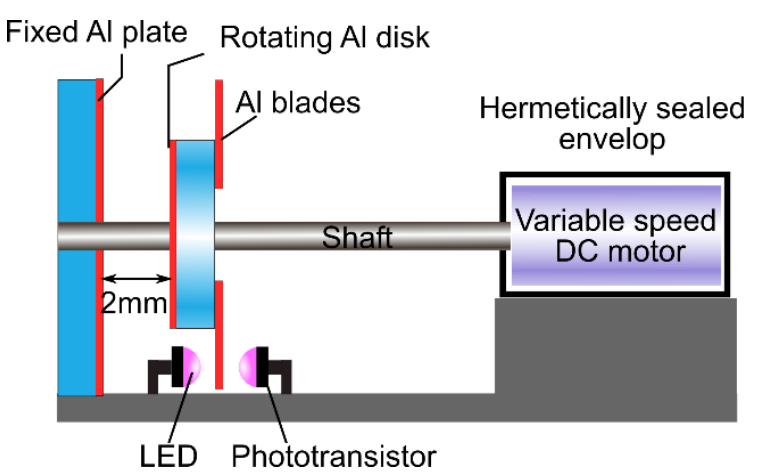

Figure 17. Schematic of the multi-property sensor using a rotating disk [84]

Zhu et al. developed an integrated oil conditioning sensor based on frequency division multiplexing to monitor wear debris, viscosity, and water/moisture content [21]. The equivalent circuit of the integrated sensor is shown in Figure 18. It consisted of eight parallel wear debris sensing channels, where the 2-layer inductive coils were used as sensing elements, one piezoelectric viscosity sensing element and one capacitive water sensing element. Frequency division multiplexing was applied on the sensing elements such that only one signal input and two signal outputs were needed, and the signal-to-noise ratio was also improved. This sensor is capable of measuring wear debris $(>50 \mu \mathrm{m})$, viscosity $(>12.4 \mathrm{cSt})$, and water content $(>50 \mathrm{ppm})$ with a throughput of 200 $\mathrm{mL} / \mathrm{min}$. However, only up to 10 wear debris sensing channels (equivalent to a throughput of 250 $\mathrm{mL} / \mathrm{min}$ ) can be installed; crosstalk between channels would arise if a larger number of channels are used. Additionally, complex post signal processing or cumbersome circuit parameter adjustment becomes inevitable for reducing the crosstalk.

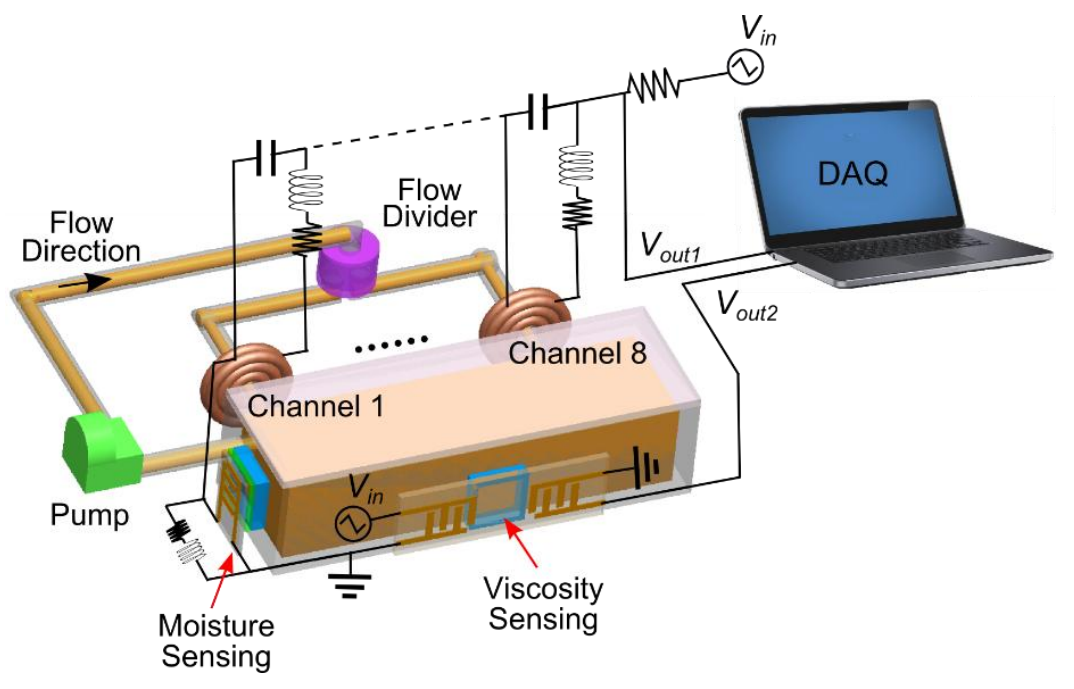


Figure 18. Measurement setup of the integrated oil property sensor by Zhu et al. [21]. Eight wear debris sensing channels were installed to increase the throughput; signal multiplexing was used to simplify the measurement circuit (only one signal input and two signal outputs were needed)

It is worth mentioning here that to date most electrochemical sensors for oil properties have not solved the cross sensitivity problem (called overlapping), i.e., the changes in permittivity and conductivity respond to changes in many properties including soot content, oxidation, fuel dilution, water/moisture content, metallic wear debris, and charged ions, etc., rather than to a specific property. Hence it is difficult to accurately determine the value of each individual property with these sensors.

To overcome the cross sensitivity problem, Zhu et al. [85] developed an electrochemical sensor array and used back propagation artificial neural network (BPNN) for detection and quantification of four oil properties, namely water content, TAN, soot content, and sulfur content. The artificial neural network has been proved effectively in processing the responses from sensors that are affected by more than one factor, and determining the relationship between the sensors and each factor [86,87]. The back propagation neural network (BPNN) is a widely used artificial neural network in untangling the overlapping of sensor responses [88,89]. Figure 19 shows the design of the microsensor array. While all the four sensing components respond to all properties, each sensor responds to the four properties differently. With an optimized BPNN, the sensor array can detect contents of water, TAN, soot, and sulfur at different concentration levels with a maximum prediction error of $18.8 \%$.

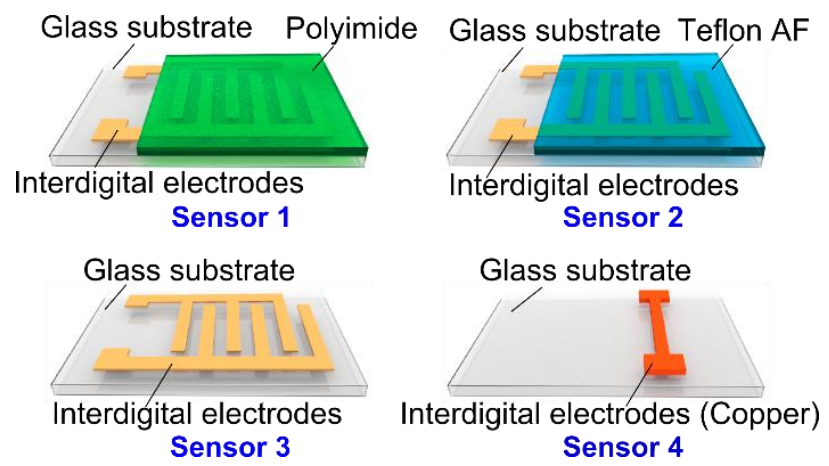

Figure 19. Schematics of the microsensor array developed by Zhu et al. [85]. Sensor 1 primarily responds to water, sensor 2 has no preference, sensor 3 primarily responds to soot, and sensor 4 primarily responds to sulfur content

To be noted that, if any of the introduced online sensors are implemented in an engine or vehicle, external engine-induced vibration can possibly add environmental noise to the measurement results. Studies have shown that during engine operation, the structural vibration frequency can be up to $200 \mathrm{~Hz}$ [90,91]. This vibration noise is picked up by the measurement circuits and induce measurement noises. However, for sensors using DC or AC excitation signals (in the $\mathrm{kHz}$ or $\mathrm{MHz}$ ), this vibration frequency can be eliminated by Fast Fourier Transform (FFT) during signal processing. For sensors based on optical/imaging methods, specialized de-blurring algorithms [92] and/or vibration compensation techniques $[93,94]$ can be used to minimize the external vibration influence.

\section{Future trends and remarks}

For online lubricating oil condition monitoring, single property sensors like wear debris sensor and viscosity sensor have achieved certain success. However, to meet the industrial needs in machine health monitoring, we believe the future trends of researches are: 
1) Development of high sensitivity wear debris and oil property sensors. Certain machines generate finer debris particles even at abnormal wear conditions. For example, for wind turbines, their abnormal wear begins to generate approximately $10 \mu \mathrm{m}$ wear debris [95]. Furthermore, in addition to lubricating oil, fuel has been used as a special lubricant for fuel injection pumps. Common contaminants and properties, including wear particle, water content, or abnormal viscosity change in fuel-lubricated systems are greatly smaller than these in oil-lubricated systems. Current sensors that can measure debris as small as $20 \mu \mathrm{m}$ and viscosity as low as $10 \mathrm{cSt}$ may be insufficient for wind turbines and fuel-lubricated machines. Thus, development of wear debris sensors, water content sensors, and viscosity sensors with higher sensitivity is needed to provide an accurate evaluation of oil or fuel lubricant conditions. On the other hand, large engines need a monitoring system with a throughput larger than $1 \mathrm{~L} / \mathrm{min}$. New sensor structure and/or advanced measurement circuit (e.g. high- order LCR resonant circuit) need to be explored to increase the throughput without sacrificing the sensitivity.

2) Development of special oil property sensors that are only sensitive to the designed 15 properties, e.g. soot content, sulfur content, and oil oxidation, etc. Current online technologies for 16 these properties either have a low sensitivity or have a large error rate because of the low selectivity 17 [95]. Possible solutions might be the development of a) highly selective sensing film that only 18 responds to the designed property, and b) online and miniature, portable sensors based on element 19 analysis techniques such as Fourier transform infrared spectroscopy (FTIR).

3) Integration of multiple sensors to collect more information regarding oil degradation (e.g. 21 22 23

\section{Acknowledgement}

wear debris, water content, viscosity, soot content, TAN, etc.). However, with more and more sensors installed in the monitoring system, cross sensitivity among sensors becomes an issue. Effective algorithms or models for data processing and information extraction to identify damage/failure for a variety of machines are needed to provide predictive maintenance and prognosis of the machine's remaining service life. Artificial neural network (ANN) [86-88] as well as principle component analysis (PCA) [96] becomes promising to effectively obtain useful information from multiple sensors because of their abilities in solving the cross sensitivity problem. Because of complex nature of lubricant in operation, new algorithm is needed to accurately pinpoint various properties of lubricant if unknown contaminants are present in the oil. Additionally, algorithm toward self-training and validation of the artificial neural network would be of great benefit to the end users.

4) Development of an efficient and fast onboard data collecting and processing algorithm/circuit associated with the integrated sensors to realize real time processing. One of the challenges is that raw data size from multiple sensors must be reduced. Possible solutions to reduce the data size as well as simplify the measurement circuits have been demonstrated based on Frequency/Time Division Multiplexing combined with Fast Fourier Transform (FFT) or Synchronized Sampling [21,22].

5) Development of wireless sensor networks (WSN) for wind turbines in remote wind farms, air planes, and marine ships, etc. [97,98]. For these machines, using cables to connect multiple sensors increases the sensor system's overall complexity, cost, and weight. Wireless sensor networks can provide new and retrofitted systems by eliminating much of the cabling, interconnects, and ultimately reduce overall system weight, and tremendously reduce the running cost. WSN also have the advantage of more tolerance in the presence of water, smoke, and fire, etc. However, data transmission reliability, data collisions between multiple sensors, and data security from the sensor networks to the remote station should be considered before cable replacement. 
1 This work is partially supported by National Science Foundation via grants CMMI-0968736 and 2 ECCS-1625544.

\section{References}

4 [1] Yan R, Gao RX. Complexity as a measure for machine health evaluation. IEEE Trans

[2] Khan MA, Starr AG. Wear debris: basic features and machine health diagnostics. Insight Non-Destructive Test Cond Monit 2006;48:470-6.

[3] Younus AMD, Yang BS. Intelligent fault diagnosis of rotating machinery using infrared thermal image. Expert Syst Appl 2012;39:2082-91.

[4] García Márquez FP, Tobias AM, Pinar Pérez JM, Papaelias M. Condition monitoring of wind turbines: Techniques and methods. Renew Energy 2012;46:169-78.

[5] Kumar M, Shankar Mukherjee P, Mohan Misra N. Advancement and current status of wear debris analysis for machine condition monitoring: a review. Ind Lubr Tribol 2013;65:3-11.

[6] Flanagan, I.M., Jordan, J.R. and Whittington HW. Wear-debris detection and analysis techniques for lubricant-based condition monitoring. J Phys E Sci Instruments, 1988;21:1011-6.

[7] Du L, Zhu X, Han Y, Zhe J. High throughput wear debris detection in lubricants using a resonance frequency division multiplexed sensor. Tribol Lett 2013;51:453-60.

[8] Cao W, Dong G, Chen W, Wu J, Xie YB. Multisensor information integration for online wear condition monitoring of diesel engines. Tribol Int 2015;82:68-77.

[9] Shen MX, Dong F, Zhang ZX, Meng XK, Peng XD. Effect of abrasive size on friction and wear characteristics of nitrile butadiene rubber (NBR) in two-body abrasion. Tribol Int 2016;103:1-11.

[10] Controls, Gill Sensors \& Controls. Oil debris sensor. https://www.gillsc.com/assets/Uploads/GScondition-CD1599-Iss-5.pdf (accessed December 20, 2016).

[11] Murali S, Xia X, Jagtiani A V, Carletta J, Zhe J. Capacitive Coulter counting: detection of metal wear particles in lubricant using a microfluidic device. Smart Mater Struct 2009;18:37001.

[12] Wen Z, Yin X, Jiang Z. Applications of electrostatic sensor for wear debris detecting in the lubricating oil. J Inst Eng Ser C 2013;94:281-6.

[13] Liu Y, Liu Z, Xie Y, Yao Z. Research on an on-line wear condition monitoring system for marine diesel engine. Tribol Int 2000;33:829-35.

[14] Keller MA, Saba CS. Monitoring of ester base lubricants by dielectric constant. Lubr Eng 1989;45:347-51.

[15] Du L, Zhe J, Carletta J, Veillette R, Choy F. Real-time monitoring of wear debris in 
[16] Du L, Zhe J, Carletta JE, Veillette RJ. Inductive Coulter counting: detection and differentiation of metal wear particles in lubricant. Smart Mater Struct 2010;19:57001.

[17] Gastops Long Live Equipment. MetalSCAN MS4000. http://www.gastops.com/wpcontent/uploads/2016/09/C008850_001.pdf (accessed December 20, 2016).

[18] Du L, Zhe J. A high throughput inductive pulse sensor for online oil debris monitoring. Tribol Int 2011;44:175-9.

[19] Du L, Zhe J. Parallel sensing of metallic wear debris in lubricants using undersampling data processing. Tribol Int 2012;53:28-34.

[20] Du L, Zhu X, Han Y, Zhao L, Zhe J. Improving sensitivity of an inductive pulse sensor for detection of metallic wear debris in lubricants using parallel LC resonance method. Meas Sci Technol 2013;24:75106.

[21] Zhu X, Du L, Zhe J. An integrated lubricant oil conditioning sensor using signal multiplexing. J Micromechanics Microengineering 2015;25:15006.

[22] Zhu X, Du L, Zhe J. A 3×3 wear debris sensor array for real time lubricant oil conditioning monitoring using synchronized sampling. Mech Syst Signal Process 2017;83:296-304.

[23] Nemarich CP, Whitesel HK, Sarkady A. On-line wear particle monitoring based on ultrasonic detection and discrimination. Mater Eval 1988;50:525-30.

[24] Xu C, Zhang P, Wang H, Li Y, Lv C. Ultrasonic echo waveshape features extraction based on QPSO-matching pursuit for online wear debris discrimination. Mech Syst Signal Process 2015;60:301-15.

[25] Du L, Zhe J. An integrated ultrasonic-inductive pulse sensor for wear debris detection. Smart Mater Struct 2013;22:25003.

[26] Hamilton A, Cleary A, Quail F. Development of a novel wear detection system for wind turbine gearboxes. IEEE Sens J 2014;14:465-73.

[27] Peng Y, Wu T, Wang S, Peng Z. Oxidation wear monitoring based on the color extraction of on-line wear debris. Wear 2015;332-333:1151-7.

[28] Wu T, Wu H, Du Y, Kwok N, Peng Z. Imaged wear debris separation for on-line monitoring using gray level and integrated morphological features. Wear 2014;316:19-29.

[29] Du L, Zhe J. On-line wear debris detection in lubricating oil for condition based health monitoring of rotary machinery. Recent Patents Electr Electron Eng 2011;4:1-9.

[30] Brouwer MD, Gupta LA, Sadeghi F, Peroulis D, Adams D. High temperature dynamic viscosity sensor for engine oil applications. Sensors Actuators, A Phys 2012;173:102-7.

[31] Agoston A, Ötsch C, Jakoby B. Viscosity sensors for engine oil condition monitoring Application and interpretation of results. Sensors Actuators, A Phys 2005;121:327-32. 

[32] O'Sullivan CK, Guilbault GG. Commercial quartz crystal microbalances - Theory and
applications. Biosens Bioelectron 1999;14:663-70.

[33] Markova L V., Makarenko VM, Semenyuk MS, Zozulya a. P. On-line monitoring of the viscosity of lubricating oils. J Frict Wear 2010;31:433-42.

[34] Markova L V., Myshkin NK, Kong H, Han HG. On-line acoustic viscometry in oil condition monitoring. Tribol Int 2011;44:963-70.

[35] Saluja A, Kalonia DS. Measurement of fluid viscosity at microliter volumes using quartz impedance analysis. AAPS PharmSciTech 2004;5:e47.

[36] Durdag K. Solid state acoustic wave sensors for real-time in-line measurement of oil viscosity. Sens Rev 2008;28:68-73.

[37] Billson D. Ultrasonic liquid viscosity sensor using mode conversion. United States patent US 20070101804, 2007.

[38] Jakoby B, Scherer M, Buskies M, Eisenschmid H. An automotive engine oil viscosity sensor. IEEE Sens J 2003;3:562-8.

[39] Salzer S, Jahns R, Piorra A, Teliban I, Reermann J, Höft M, et al. Tuning fork for noise suppression in magnetoelectric sensors. Sensors Actuators, A Phys 2016;237:91-5.

[40] Heinisch M, Voglhuber-Brunnmaier T, Reichel EK, Dufour I, Jakoby B. Application of resonant steel tuning forks with circular and rectangular cross sections for precise mass density and viscosity measurements. Sensors Actuators, A Phys 2015;226:163-74.

[41] Mortier RM, Fox MF, Orszulik ST. Chemistry and technology of lubricants. 3rd ed. London: Springer; 2010.

[42] Lancaster JK. A review of the influence of environmental humidity and water on friction, lubrication and wear. Tribol Int 1990;23:371-89.

[43] Science C, Systems E. An immersible relative saturation moisture sensor with application to transformer oil. Prop. Appl. Dielectr. Mater. Proc. 3rd Int. Conf. IEEE, 1991, p. 8-11.

[44] Yadav BC, Srivastava R, Dwivedi CD, Pramanik P. Moisture sensor based on ZnO nanomaterial synthesized through oxalate route. Sensors Actuators, B Chem 2008;131:216-22.

[45] Balde M, Vena A, Sorli B. Fabrication of porous anodic aluminium oxide layers on paper for humidity sensors. Sensors Actuators, B Chem 2015;220:829-39.

[46] Raadnui S, Kleesuwan S. Low-cost condition monitoring sensor for used oil analysis. Wear 2005;259:1502-6.

[47] Schüller RB, Gundersen T, Halleraker M, Engebretsen B. Measurement of water concentration in oil/water dispersions with a circular single-electrode capacitance probe. IEEE Trans Instrum Meas 2004;53:1378-83.

[48] Holzki M, Fouckhardt H, Klotzbücher T. Evanescent-field fiber sensor for the water content in lubricating oils with sensitivity increase by dielectrophoresis. Sensors Actuators, 
A Phys 2012;184:93-7.

[49] Mueller CJ, Pitz WJ, Pickett LM, Martin GC, Siebers DL, Westbrook CK. Effects of oxygenates on soot processes in DI diesel engines: experiments and numerical simulations. SAE Techical Pap 2003;1:1791.

[50] Laget O, Malbec L-M, Kashdan J, Dronniou N, Boissard R, Gastaldi P. Experimental and numerical investigations on the mechanisms leading to the accumulation of particulate matter in lubricant oil. SAE Int J Engines 2016;9:2016-01-2182.

[51] Hu E, Hu X, Liu T, Fang L, Dearn KD, Xu H. The role of soot particles in the tribological behavior of engine lubricating oils. Wear 2013;304:152-61.

[52] Storey, J.M., Curran, S., Dempsey, A.B., Lewis Sr, S.A. and Reitz R. Investigation of the potential impact of lubricant contribution to the formation of particulate matter with reactivity controlled compression ignition on light-duty diesel engines. Emiss Control Sci Technol 2014;1.

[53] George S, Balla S, Gautam M. Effect of diesel soot contaminated oil on engine wear. Wear 2007;262:1113-22.

[54] Clague AD., Donnet J., Wang T., Peng JC. A comparison of diesel engine soot with carbon black. Carbon N Y 1999;37:1553-65.

[55] Jun HB, Kiritsis D, Gambera M, Xirouchakis P. Predictive algorithm to determine the suitable time to change automotive engine oil. Comput Ind Eng 2006;51:671-83.

[56] Ulrich C, Petersson H, Sundgren H, Björefors F, Krantz-Rülcker C. Simultaneous estimation of soot and diesel contamination in engine oil using electrochemical impedance spectroscopy. Sensors Actuators, B Chem 2007;127:613-8.

[57] Smiechowski MF, Lvovich VF. Iridium oxide sensors for acidity and basicity detection in industrial lubricants. Sensors Actuators, B Chem 2003;96:261-7.

[58] Blaine S, Savage PEP. Reaction pathways in lubricant degradation. 3. Reaction model for n-hexadecane autoxidation. Ind Eng Chem Res 1992;31:69-75.

[59] Soleimani M, Sophocleous M, Wang L, Atkinson J, Hosier IL, Vaughan AS, et al. Base oil oxidation detection using novel chemical sensors and impedance spectroscopy measurements. Sensors Actuators, B Chem 2014;199:247-58.

[60] Soleimani M, Sophocleous M, Glanc M, Atkinson J, Wang L, Wood RJK, et al. Engine oil acidity detection using solid state ion selective electrodes. Tribol Int 2013;65:48-56.

[61] Moon S-I, Paek K-K, Lee Y-H, Kim J-K, Kim S-W, Ju B-K. Multiwall carbon nanotube sensor for monitoring engine oil degradation. Electrochem Solid-State Lett 2006;9:H78.

[62] Ippoliti L, Steimes J, Hendrick P. Investigation on an oil aeration measurement technique for the study of pump performance in an aircraft engine lubrication system. Vol. 5C Heat Transf., ASME; 2015, p. V05CT15A016.

37 [63] Fowle TI. Aeration in lubricating oils. Tribol Int 1981;14:151-7. 
[65] Delta Services Industrials. Lubricant aeration. http://www.deltabeam.net/en/product/lubricant-aeration (accessed December 20, 2016).

[66] Miettinen J, Andersson P. Acoustic emission of rolling bearings lubricated with contaminated grease. Tribol Int 2000;33:777-87.

[67] Tandon N, Ramakrishna KM, Yadava GS. Condition monitoring of electric motor ball bearings for the detection of grease contaminants. Tribol Int 2007;40:29-36.

[68] Zhao M, Lin J, Xu X, Li X. Multi-fault detection of rolling element bearings under harsh working condition using imf-based adaptive envelope order analysis. Sensors (Switzerland) 2014;14:20320-46.

[69] He Y, Zhao Z, Luo T, Lu X, Luo J. Failure analysis of journal bearing used in turboset of a power plant. Mater Des 2013;52:923-31.

[70] Cann PM, Doner JP, Webster MN, Wikstrom V. Grease degradation in rolling element bearings. Tribol Trans 2001;44:399-404.

[71] Industrial Technology. Online condition monitoring of grease in rolling bearings. http://www.industrialtechnology.co.uk/products--online-condition-monitoring-of-greasein-rolling-bearings.html (accessed December 20, 2016).

[72] Aranzabe a, Aranzabe E, Marcaide a, Ferret R, Terradillos J, Ameye J, et al. Comparing different analytical techniques to monitor lubricating grease degradation. NLGI Spokesm 2006;70:17-30.

[73] Tondon N, Choudhury A. A review of vibration and acoustics measurement methods for the detection of defects in rolling element bearing. Tribol Int 1999;32:469-80.

[74] Boškoski P, Petrovičič J, Musizza B, Juriičić D. Detection of lubrication starved bearings in electrical motors by means of vibration analysis. Tribol Int 2010;43:1683-92.

[75] Gutowski P, Leus M. The effect of longitudinal tangential vibrations on friction and driving forces in sliding motion. Tribol Int 2012;55:108-18.

[76] Kiral Z, Karagülle H. Simulation and analysis of vibration signals generated by rolling element bearing with defects. Tribol Int 2003;36:667-78.

[77] Yoo SS, Kim DE. Effects of vibration frequency and amplitude on friction reduction and wear characteristics of silicon. Tribol Int 2016;94:198-205.

[78] Sheng S, Zhang L, Gao RX. A systematic sensor-placement strategy for enhanced defect detection in rolling bearings. IEEE Sens J 2006;6:1346-54.

[79] Cai Y, He Y, Li A, Zhao J, Wang T. Application of Wavelet to Gearbox Vibration Signals for Fault Detection. Adv Comput Control (ICACC), 2010 2nd Int Conf 2010;192:441-4.

[80] Baydar N, Chen Q, Ball A, Kruger U. Detection of incipient tooth defect in helical gears using multivariate statistics. Mech Syst Signal Process 2001;15:303-21. 
1 [81] Raj AS, Murali N. Early classification of bearing faults using morphological operators and fuzzy inference. IEEE Trans Ind Electron 2013;60:567-74.

[82] Wu T, Wu H, Du Y, Peng Z. Progress and trend of sensor technology for on-line oil monitoring. Sci China Technol Sci 2013;56:2914-26.

[83] Preethichandra DMG, Shida K. Actual condition monitoring of engine oil through an intelligent multi-functional sensing approach. Ind. Electron. Soc. 2000. IECON 2000. 26th Annu. Conf. IEEE, 2000, p. 2383-7.

[84] Duchowski JK, Mannebach H. A novel approach to predictive maintenance: a portable, multi-component MEMS sensor for on-line monitoring of fluid condition in hydraulic and lubricating systems. Tribol Trans 2006;49:545-53.

[85] Zhu X, Du L, Liu B, Zhe J. A microsensor array for quantification of lubricant contaminants using a back propagation artificial neural network. J Micromechanics Microengineering 2016;26:65005.

[86] Sadegh H, Mehdi AN, Mehdi A. Classification of acoustic emission signals generated from journal bearing at different lubrication conditions based on wavelet analysis in combination with artificial neural network and genetic algorithm. Tribol Int 2016;95:42634.

[87] Rai A, Upadhyay SH. A review on signal processing techniques utilized in the fault diagnosis of rolling element bearings. Tribol Int 2016;96:289-306.

[88] Mimendia A, Gutiérrez JM, Alcañiz JM, del Valle M. Discrimination of soils and assessment of soil fertility using information from an ion selective electrodes array and artificial neural networks. Clean - Soil, Air, Water 2014;42:1808-15.

[89] Kotzalas MN, Doll GL. Tribological advancements for reliable wind turbine performance. Philos Trans A Math Phys Eng Sci 2010;368:4829-50.

[90] Seshadrinath J, Singh B, Panigrahi BK. Vibration analysis based interturn fault diagnosis in induction machines. IEEE Trans Ind Informatics 2014;10:340-50.

[91] Bohn C, Cortabarria A, Härtel V, Kowalczyk K. Active control of engine-induced vibrations in automotive vehicles using disturbance observer gain scheduling. Control Eng Pract 2004;12:1029-39. doi:10.1016/j.conengprac.2003.09.008.

[92] McCarthy DMJ, Chandler JH, Palmeri A. Monitoring dynamic structural tests using image deblurring techniques. Key Eng Mater 2013;569-570:932-9.

[93] Zhu F, Zhang X, Xia L, Guo Z, Zhang Y. Active compensation method for light source frequency drifting in $\Phi$-OTDR sensing system. IEEE Photonics Technol Lett 2015;27:2523-6.

[94] Maret Y, Member S, Angelosante D, Steiger O, Member S. Vibration sensitivity reduction of photoacoustic gas analyzers. IEEE Sens J 2014;14:2841-50.

[95] Jakoby B, Vellekoop MJ. Physical sensors for liquid properties. IEEE Sens J 2011;11:3076-85. 
[96] Wang J, Wang X. A wear particle identification method by combining principal

2 component analysis and grey relational analysis. Wear 2013;304:96-102.

3 [97] Singh S, Galar D, Baglee D, Björling SE. Self-maintenance techniques: A smart approach

4 towards self-maintenance system. Int J Syst Assur Eng Manag 2014;5:75-83.

5 [98] Cho J, Park S. Capacitive sensor for automotive engine oil degradation using wireless 6 network. 2010 Int Symp Adv Packag Mater Microtech 2010:88-91. 